\title{
Drought Induced Changes in Growth, Osmolyte Accumulation and Antioxidant Metabolism of Three Maize Hybrids
}

\author{
Shakeel A. Anjum 1,2†, Umair Ashraf ${ }^{3,4+}$, Mohsin Tanveer', ${ }^{2,5}$ Imran Khan'2, \\ Saddam Hussain'2,6, Babar Shahzad², Ali Zohaib², Farhat Abbas ${ }^{3,7}$, \\ Muhammad F. Saleem ${ }^{2}$, Iftikhar Ali ${ }^{2}$ and Long C. Wang ${ }^{1 *}$
}

\begin{abstract}
${ }^{1}$ College of Agronomy and Biotechnology, Southwest University, Chongqing, China, ${ }^{2}$ Department of Agronomy, University of Agriculture, Faisalabad, Pakistan, ${ }^{3}$ Department of Crop Science and Technology, College of Agriculture, South China Agricultural University, Guangzhou, China, ${ }^{4}$ Scientific Observing and Experimental Station of Crop cultivation in South China, Ministry of Agriculture, Guangzhou, China, ${ }^{5}$ School of Land and Food, University of Tasmania, Hobart, TAS, Australia, ${ }^{6}$ College of Plant Science and Technology, Huazhong Agricultural University, Wuhan, China, ${ }^{7}$ The Research Center for Ornamental Plants, College of Horticulture, South China Agricultural University, Guangzhou, China
\end{abstract}

\section{OPEN ACCESS}

Edited by:

Vasileios Fotopoulos,

Cyprus University of Technology,

Cyprus

Reviewed by:

Mirza Hasanuzzaman,

Sher-e-Bangla Agricultural University,

Bangladesh

Agostino Sorgona',

Mediterranea University of Reggio

Calabria, Italy

*Correspondence:

Long C. Wang

wanglc@swu.edu.cn

tThese authors have contributed equally to this work.

Specialty section:

This article was submitted to Crop Science and Horticulture, a section of the journal

Frontiers in Plant Science

Received: 29 September 2016 Accepted: 12 January 2017 Published: 06 February 2017

Citation:

Anjum SA, Ashraf U, Tanveer M, Khan I, Hussain S, Shahzad B, Zohaib A, Abbas F, Saleem MF, Ali I and Wang LC (2017) Drought Induced Changes in Growth,

Osmolyte Accumulation and Antioxidant Metabolism of Three Maize Hybrids. Front. Plant Sci. 8:69. doi: 10.3389/fpls.2017.00069
Consequences of drought stress in crop production systems are perhaps more deleterious than other abiotic stresses under changing climatic scenarios. Regulations of physio-biochemical responses of plants under drought stress can be used as markers for drought stress tolerance in selection and breeding. The present study was conducted to appraise the performance of three different maize hybrids (Dong Dan 80, Wan Dan 13, and Run Nong 35) under well-watered, low, moderate and SD conditions maintained at $100,80,60$, and $40 \%$ of field capacity, respectively. Compared with well-watered conditions, drought stress caused oxidative stress by excessive production of reactive oxygen species (ROS) which led to reduced growth and yield formation in all maize hybrids; nevertheless, negative effects of drought stress were more prominent in Run Nong 35. Drought-induced osmolyte accumulation and strong enzymatic and nonenzymatic defense systems prevented the severe damage in Dong Dan 80. Overall performance of all maize hybrids under drought stress was recorded as: Dong Dan $80>$ Wan Dan 13 > Run Nong 35 with 6.39, 7.35, and 16.55\% yield reductions. Consequently, these biochemical traits and differential physiological responses might be helpful to develop drought tolerance genotypes that can withstand water-deficit conditions with minimum yield losses.

Keywords: antioxidant defense, agronomic traits, drought, maize, ROS, yield formation

\section{INTRODUCTION}

Drought stress imposes drastic effects on plant growth and development, agronomic traits and yield formation by altering physio-anatomical mechanisms. It disturbs plant-water relations, photosynthetic gas exchange capacities, cell turgor, source-sink relationships and various metabolic events in plants (Anjum et al., 2011b). Drought-induced production of reactive oxygen species

Abbreviations: APX, ascorbate peroxidase; AsA, total ascorbate; BY, biological yield; CAT, catalase; DAP, days after planting; DHA, de hydro ascorbate; DHAR, dehydroascorbate reductase; FC, field capacity; FP, free proline; GSH, reduced glutathione; GSSG, oxidized glutathione; GY, grain yield; LD, low drought; MDHAR, monodehydroascorbate reductase; MRD, moderate drought; POD, peroxidase; SD, severe drought; SOD, superoxide dismutase; SP, soluble protein; SS, Soluble sugars; SWD, shoot dry weight; TC, total carbohydrates; TFA, total free amino acids; TPC, total phenolic contents. 
(ROS) in terms of superoxide anions $\left(\mathrm{O}_{2}^{-}\right)$, singlet oxygen $\left(\mathrm{O}_{2}^{1}\right)$, hydroxyl radicals $\left(\mathrm{OH}^{-}\right)$, hydrogen peroxide $\left(\mathrm{H}_{2} \mathrm{O}_{2}\right)$ and alkoxy radicals (RO) harms the cell membranes and damages the proteins, lipids and nucleic acids ultimately leading to cell death (Munné-Bosch and Penuelas, 2003).

Osmotic adjustment is an innate behavior of plants which helps them in maintaining water balance by synthesizing different osmolytes/solutes. These solutes protect cellular structures and functions as well as maintain water balance and delay dehydrative damage by maintaining cell turgor and other physiological mechanisms under water-deficit conditions (Taiz and Zeiger, 2006). Osmolytes further improve the carbohydrate partitioning during reproductive stages of the plants and improve final yield (Subbarao et al., 2000). Generally, proline accumulation increases under stress conditions, which not only helps in maintaining cell turgor but is also involved in quenching free radicals, maintaining sub-cellular structures, and buffering cellular redox potential (Ashraf and Foolad, 2007). Previously, increased protein contents, SS, total carbohydrates, and phenolic contents were also reported in maize plants under water-limited conditions (Anjum et al., 2011a,b,c). Anjum et al. (2014) also reported that lipids and proteins are the main target sites of oxidative stress in plants exposed to abiotic stresses. Furthermore, Maksup et al. (2014) also found enhanced protein accumulation in tolerant rice cultivars under water stress conditions.

Plants also possess an efficient antioxidant (enzymatic and non-enzymatic) defense system to cope with ROS-induced oxidative stress (Anjum et al., 2011b,c; Ashraf et al., 2015). Both enzymatic, i.e., APX, SOD, peroxidase (POD), catalase (CAT), DHAR, and MDHAR as well as non-enzymatic, i.e., AsA, DHA, GSH, GSSG antioxidants minimize the oxidative damage under stressful conditions. The contribution of both enzymatic and non-enzymatic antioxidants may ensure the stress tolerance in plants subjected to a long-term drought stress (Sharma et al., 2012). These antioxidants have been reported to contribute directly or indirectly in drought tolerance of maize. For instance, Adebayo and Menkir (2015) stated that sustained yields in maize under drought stress were directly related to better antioxidant activities. Farooq et al. (2009) also concluded that increased activities/levels of enzymatic and nonenzymatic antioxidants may improve the drought tolerance by scavenging ROS.

Maize (Zea mays L.) is well-recognized as one of the most important cereals worldwide while China ranked second in its production and consumption after USA (Gale et al., 2014). Normally, it needs $500-800 \mathrm{~mm}$ of water during its life cycle (80-110 days) (Critchley and Klaus, 1991); however, occurrence of drought stress during maize growth period may hamper the nitrogen and water use efficiencies leading to significant yield losses (Saini and Westgate, 2000; Ashraf et al., 2016). Droughtrelated physiological and metabolic changes might be helpful in determining the sensitivity or tolerance of a plant under water deficit conditions and can be used as stress indicators. For the selection and screening of drought-tolerant genotypes as well as for agronomic and genetic engineering, the expression of tolerance mechanisms and identification of most effective antioxidants in plants must be studied in detail at different drought levels (Xing and $\mathrm{Wu}, 2012$ ). Therefore, the present study was conducted to assess the drought-induced oxidative damage in terms of ROS accumulation, and possible protection by osmoregulation and/or activation of enzymatic and nonenzymatic antioxidative defense systems. Involvement of these physio-biochemical mechanisms in maize growth and yield response under drought stress were also studied to get better insights of maize tolerance mechanism(s) to drought stress conditions.

\section{MATERIALS AND METHODS}

\section{Plant Material and Growth Conditions}

A pot experiment was conducted in a glass house at the College of Agronomy and Biotechnology, Southwest University, Chongqing, China (latitude $29^{\circ} 49^{\prime} 32^{\prime \prime} \mathrm{N}$, longitude $106^{\circ} 26^{\prime}$ $02^{\prime \prime} \mathrm{E}$ and altitude $220 \mathrm{~m}$ ) during spring, 2013. The seeds of three maize hybrids, i.e., Dong Dan 80, Wan Dan 13, and Run Nong 35 were obtained from Liaoning Dongya Seed Company Ltd., Liaoning, China. Seeds of all maize hybrids were sown in PVC nursery trays (two seeds per hill). Two week old seedlings were transplanted (two seedlings per pot) into plastic pots $(34 \mathrm{~cm}$ in diameter, $24 \mathrm{~cm}$ in depth) filled with sandy loam soil and farmyard manure in 3:1 proportion. Total weight of each pot was $16 \mathrm{~kg}$ after filling with air-dried soil. The experimental soil contained $2.08 \mathrm{~g} \mathrm{~kg}^{-1}$ total nitrogen, $3.77 \mathrm{~g} \mathrm{~kg}^{-1}$ total phosphorous, $12.33 \mathrm{~g} \mathrm{~kg}^{-1}$ total potassium, $89.37 \mathrm{mg} \mathrm{kg}^{-1}$ alkalihydro nitrogen content, $30.14 \mathrm{mg} \mathrm{kg}^{-1}$ available phosphorous, $54.88 \mathrm{mg} \mathrm{kg}^{-1}$ available potassium, $14.76 \mathrm{~g} \mathrm{~kg}^{-1}$ organic matter and $6.48 \mathrm{pH}$. Fertilizer was applied to all pots at $15 \mathrm{~g}$ per pot (5 $\mathrm{g}$ at planting, $5 \mathrm{~g} 20 \mathrm{DAP}$ and $5 \mathrm{~g}$ at $40 \mathrm{DAP}$ ), containing 15-5-5\% N, $\mathrm{P}_{2} \mathrm{O}_{5}$ and $\mathrm{K}_{2} \mathrm{O}$, respectively. The average night and day temperature of the glass house was in the range of $21-33^{\circ} \mathrm{C}$ during crop growth period, while the relative humidity $(\mathrm{RH})$ was $52-88 \%$ in the morning and $49-83 \%$ in the afternoon.

\section{Drought Treatments}

The maize plants were allowed to grow under normal conditions up to pre-tasseling stage. At $45 \mathrm{DAP}$, three different levels of drought stress with respect to FC, i.e., LD ( $80 \% \mathrm{FC}), \mathrm{MRD}$ $(60 \%$ FC) and SD (40\% FC) were imposed, while a well-watered control (Ck) with $100 \%$ FC was maintained for comparison. The stress treatments were regularly monitored by a moisture meter TRIME-EZ/-IT (IMKO Micromodultechnik GmbH, Germany) while the specified drought treatments were applied until crop maturity. The treatments were arranged in a completely randomized design (CRD) under factorial arrangement. Each treatment was replicated thrice, and there were five pots per replicate.

\section{Biochemical Assays}

Healthy, undamaged and fully expanded plant leaves (third from the top) from each replication were sampled at 7 days after imposition of drought treatments to assess the osmolytes, ROS, and enzymatic and non-enzymatic antioxidants. After washing 
with double distilled water, leaves were frozen in liquid $\mathrm{N}_{2}$ and stored at $-80^{\circ} \mathrm{C}$ until biochemical analyses.

\section{ROS Production}

The production rate of superoxide ion $\left(\mathrm{O}_{2}{ }^{-}\right)$was determined according to Elstner and Heupel (1976). Briefly, fresh leaf samples $(0.5 \mathrm{~g})$ were homogenized with $65 \mathrm{mM}$ phosphate buffer $(\mathrm{pH} 7.8)$ and centrifuged at $5,000 \times g$ for $15 \mathrm{~min}$ at $4^{\circ} \mathrm{C}$. A mixture of $2 \mathrm{ml}$ containing phosphate buffer $(0.9 \mathrm{ml}), 10 \mathrm{mM}$ hydroxylamine hydrochloride $(0.1 \mathrm{ml})$ and supernatant $(1 \mathrm{ml})$ was incubated at $25^{\circ} \mathrm{C}$ for $30 \mathrm{~min}$, then $1 \mathrm{ml}$ of $17 \mathrm{mM}$ sulphanilamide and $7 \mathrm{mM}$ $\alpha$-naphthylamine were added and incubated at $25^{\circ} \mathrm{C}$ for $20 \mathrm{~min}$. The change in absorbance was measured at $530 \mathrm{~nm}$. A standard curve with $\mathrm{NO}_{2}{ }^{-}$was used to calculate the production rate of $\mathrm{O}_{2}{ }^{-}$from the chemical reaction of $\mathrm{O}_{2}{ }^{-}$and hydroxylamine. The $\mathrm{H}_{2} \mathrm{O}_{2}$ content was assayed according to the method described by Mukherjee and Choudhuri (1983).

\section{Lipid Peroxidation Rate and Lipoxygenase (LOX) Activity}

Malenoaldehyde was measured spectro-photometrically using the thiobarbituric (TBA) method according to Dhindsa et al. (1981). An aliquot of enzyme solution $(2 \mathrm{ml})$ was added to a tube containing $1 \mathrm{ml} 20 \%$ trichloroacetic acid (TCA) and $0.5 \%$ TBA. The mixture was heated in a water bath at $95^{\circ} \mathrm{C}$ for $30 \mathrm{~min}$, cooled to room temperature and then centrifuged at $14,000 \mathrm{rmp}$ for $10 \mathrm{~min}$. The absorbance was read at $532 \mathrm{~nm}$ and non-specific absorbance at $600 \mathrm{~nm}$ was subtracted from it. The MDA content was calculated by using an extinction coefficient of $155 \mathrm{mM}^{-1} \mathrm{~cm}^{-1}$.

Lipoxygenase (LOX) activity was measured according to Minguez-Mosquera et al. (1993). The absorbance was read at $234 \mathrm{~nm}$ and the activity of LOX was expressed as nmol min ${ }^{-1}$ $\mathrm{mg}^{-1}$ protein. Thiobarbituric acid reactive substances (TBARS) in leaf tissues were evaluated as described by Cakmak and Horst (1991). Briefly, fresh leaf samples $(0.5 \mathrm{~g})$ were homogenized in $4 \mathrm{ml}$ of $1 \%$ TCA and then $1 \mathrm{ml}$ of supernatant was mixed with $3 \mathrm{~mL}$ of $0.5 \% \mathrm{TBA}$ in $20 \%$ TCA. The vials were closed tightly and placed in a water bath at $95^{\circ} \mathrm{C}$ for $2 \mathrm{~h}$. To stop the reaction, vials were cooled down in an ice bath. The absorbance was read at 532 and $660 \mathrm{~nm}$. Membrane permeability was determined by assessing the electrolyte leakage (EL) following the method of Lutts et al. (1996). The EL was calculated as: $\mathrm{EL}=\left(\mathrm{EC}_{1} / \mathrm{EC}_{2}\right) \times 100$

\section{Osmolyte Accumulation Profiles}

Free proline (FP) content was assessed in fresh leaf samples $(0.5 \mathrm{~g})$ following the method of Bates et al. (1973) using ninhydrin. The reaction mixture was extracted with $5 \mathrm{ml}$ toluene, cooled to room temperature and absorbance was read at $520 \mathrm{~nm}$. TC were estimated by the phenol-sulphuric acid method as devised by Dubois et al. (1956). The absorbance was read at $485 \mathrm{~nm}$ against diluted sulphuric acid $(5+2, v / v)$ at the same wavelength. Total carbohydrate contents were calculated by measuring the difference between these two readings. SS were estimated by the anthrone-sulphuric method following Fales (1951). Fresh leaves $(0.5 \mathrm{~g})$ were put into $15 \mathrm{ml}$ distilled water and boiled in a water bath for $20 \mathrm{~min}$. After cooling, $5 \mathrm{ml}$ anthrone was added to $0.1 \mathrm{ml}$ of boiled sample. The $3 \mathrm{ml}$ of boiled sample was transferred to a cuvette and the absorbance was read at $620 \mathrm{~nm}$. The TPC was estimated following a slightly modified method of Ainsworth and Gillespie (2007) by using Folin-Ciocalteu reagent. The reaction mixture was composed of $0.1 \mathrm{ml}$ extract, $7.9 \mathrm{ml}$ distilled water, $0.5 \mathrm{ml}$ Folin-Ciocalteu reagent, and $1.5 \mathrm{ml}$ of $20 \%$ sodium carbonate. The absorbance of the resulting mixtures was read at $750 \mathrm{~nm}$ and TPC were measured from a standard curve developed by gallic acid (GA) standards. SP content was estimated by the Bradford (1976) method. Bradford solution $(1 \mathrm{ml})$ was mixed with $100 \mu \mathrm{l}$ crude extract and absorbance was read at $595 \mathrm{~nm}$. The protein contents were estimated from a standard curve. TFA were assessed by using the ninhydrin colorimetric method of Huang et al. (2010). The absorbance was read at $568 \mathrm{~nm}$.

\section{Antioxidant Activity}

Enzymatic antioxidants

Superoxide dismutase (EC 1.15.1.1) activity was assayed using the kit (A001-1) provided by Nanjing Jiancheng Bioengineering Institute, China. One unit of SOD activity was defined as the amount of enzyme required for $1 \mathrm{mg}$ tissue proteins in $1 \mathrm{ml}$ of a reaction mixture to raise SOD inhibition rates to $50 \%$ at $550 \mathrm{~nm}$ (Tecan infinite M200, Swit). Peroxidase (POD, EC1.11.1.7) activity was determined following the method of Upadhyaya et al. (1985). The absorbance of the reaction mixture containing $100 \mu \mathrm{l}$ enzyme extract, $50 \mathrm{mM}$ phosphate buffer ( $\mathrm{pH} 7.0$ ), $28 \mu \mathrm{l}$ guaiacol and $19 \mu \mathrm{H} \mathrm{H}_{2} \mathrm{O}_{2}$ was read at 420 with a $30 \mathrm{~s}$ interval up to 2 min and used the absorbance change 0.01 as a POD activity. Catalase (CAT, EC 1.11.1.6) activity was determined by using the kit (A007-1) purchased from Nanjing Jiancheng Bioengineering Institute, China. One unit of CAT activity was estimated as the amount of enzyme that decomposes $1 \mu \mathrm{mol} \mathrm{H}_{2} \mathrm{O}_{2}$ at $405 \mathrm{~nm}$ $\mathrm{sec}^{-1}$ in $1 \mathrm{mg}$ fresh tissue proteins (Tecan infinite M200, Swit). APX (EC 1.11.1.11) was assayed according to Nakano and Asada (1981). The reaction mixture $(3 \mathrm{ml})$ contained $100 \mu \mathrm{l}$ enzyme extract, $100 \mathrm{mM}$ phosphate buffer ( $\mathrm{pH} 7.0$ ), $0.3 \mathrm{mM}$ ascorbic acid, $0.1 \mathrm{mM}$ EDTA-Na2, and $0.06 \mathrm{mM} \mathrm{H}_{2} \mathrm{O}_{2}$. The change in absorbance after adding $\mathrm{H}_{2} \mathrm{O}_{2}$ was read at $290 \mathrm{~nm}$ for $2 \mathrm{~min}$ at every $30 \mathrm{~s}$ interval. MDHAR (EC 1.6.5.4) was assayed by following the method of Foyer et al. (1989). The enzyme activity was assayed by following the change in wavelength at $340 \mathrm{~nm}$ after adding ascorbate oxidase whereas DHAR (EC 1.8.5.1) was assayed by following the method described by Doulis et al. (1997). A $1 \mathrm{ml}$ reaction mixture contained $50 \mu \mathrm{l}$ of enzyme extract, $1 \mathrm{ml}$ of $50 \mathrm{mM}$ potassium phosphate buffer ( $\mathrm{pH} 7.0$ ), $0.2 \mathrm{mM}$ DHA, $2.5 \mathrm{mM}$ GSH, 1, and $0.1 \mathrm{mM}$ EDTA. The absorbance was read at $265 \mathrm{~nm}$.

\section{Non-enzymatic antioxidants}

Total ascorbate (AsA + DHA) and reduced ascorbate (AsA) contents were estimated according to Hodges et al. (1996). A $200 \mu \mathrm{l}$ of supernatant was mixed with $500 \mu \mathrm{l}$ of $150 \mathrm{mM} \mathrm{K}_{2} \mathrm{PO}_{4}$ buffer (pH 7.0) containing $5 \mathrm{mM}$ EDTA and $100 \mu \mathrm{l}$ of $10 \mathrm{mM}$ dithiothreitol to reduce DHA to AsA. After $15 \mathrm{~min}, 100 \mu \mathrm{l}$ of $0.5 \%$ $\mathrm{N}$-ethylmaleimide was added to the reaction mixture at $25^{\circ} \mathrm{C}$ 
to remove extra dichlorodiphenyltrichloroethane (DDT). To determine AsA, $200 \mu 1$ deionized water was used instead of DTT and N-ethylmaleimide. Color appeared in both mixtures with the addition of $400 \mu \mathrm{l}$ of $44 \%$ o-phosphoric acid, $400 \mu \mathrm{l}$ of $10 \%$ trichloro acetic acid (TCA), $200 \mu \mathrm{l}$ of $30 \mathrm{~g} \mathrm{l}^{-1} \mathrm{FeCl}_{3}$ and $400 \mu \mathrm{l}$ of a,a'-dipyridyl in $70 \%(v / v)$ ethanol. The solutions were placed at $40^{\circ} \mathrm{C}$ for $1 \mathrm{~h}$ and absorbance was read at $525 \mathrm{~nm}$. Ascorbate contents were estimated from a standard curve whereas the amount of DHA was calculated from the difference between the total (AsA + DHA) and reduced ascorbate (AsA). Total glutathione (GSH + GSSG) and glutathione disulphide (GSSG) contents were measured by the method of Anderson (1985). The amount of GSH was calculated from the difference between the total glutathione and GSSG.

\section{Growth and Yield}

Leaf area of maize plants was recorded with leaf area meter (LiCor 3100, Li-Cor, Lincoln, NE, USA) while a meter scale and an electronic weighing balance were used to measure plant height and biomass accumulation, respectively. Before recording the plant dry biomass, harvested plants were cut into pieces and kept in an oven at $80^{\circ} \mathrm{C}$ until constant weight. To determine growth and yield related attributes, 30 plants ( 10 plants from each replicate) were sampled randomly and harvested at maturity. The harvested plants were sun-dried (in an open place) and the ears were shelled manually to record GY per plant. The total plant dry biomass was weighed for each treatment and regarded as BY. To record 100-kernel weight, three random samples of 100-kernels were taken from the seed lot of each treatment, weighed and averaged. Harvest index (HI) was calculated as the percent ratio of GY and BY.

\section{Statistical Analysis}

The data collected were statistically analyzed following the analysis of variance technique using SPSS 16.0 (SPSS, Chicago, IL, USA) software whilst the differences amongst treatments were separated according to Newman-Keuls tests at a significance level of 5\%. SigmaPlot 9.0 (Systat Software Inc., San Jose, CA, USA) was used for graphical presentation of the data.

\section{RESULTS}

\section{Variations in Agronomic Traits and Maize Yield under Drought Stress}

Drought stress severely inhibited the agronomic traits and yield of maize, however, all three maize hybrids showed differential response to drought stress. Compared with well-watered control, SD stress (40\% FC) significantly reduced the leaf area, shoot fresh and dry weights, number of leaves/plant, kernel rows/ear, kernels/ear, 100-grain weight, GY and BY of all three maize hybrids (Tables 1 and 2). Although, a decreasing trend was observed with increase in drought stress levels in all the tested hybrids, nonetheless, drought-induced adversities were more prominent in Run Nong 35 than those in Dong Dan 80 or Wan Dan 13 (Table 1 and 2).

\section{ROS Production and LOX Activity in Maize Hybrids Response to Drought Stress}

The levels of ROS accumulation and membrane damage in all maize hybrids were increased under drought stress. When compared with well-watered control, drought stress treatments increased the values of MDA, $\mathrm{O}_{2}{ }^{-}, \mathrm{H}_{2} \mathrm{O}_{2}$, TBARS, EL, and LOX in the range of $10-46 \%$ in Run Nong 35, 9-34\% in Wan Dan 13 , and $5-24 \%$ in Dong Dan 80, respectively. Overall, oxidative stress in terms of ROS production was increased with increased drought levels with more severe oxidative stress at maximum level of drought stress (40\% FC). Additionally, low ROS activity and less membrane damage were recorded in Dong Dan 80 followed by Wan Dan 13. However, the maximum oxidative damage in Run Nong 35 indicated its sensitivity to drought stress (Figures 1A-F).

\section{Osmolytes Accumulation in Maize Hybrids in Response to Drought Stress}

Drought stress triggered the production and accumulation of different osmolytes in all maize hybrids. Concentrations of proline, carbohydrates, SS, phenolics, proteins, and TFA were considerably higher under SD conditions as compared to wellwatered control. Accumulations of these osmolytes in all maize hybrids were increased with the severity of drought stress ( $\mathrm{SD}>\mathrm{MRD}>\mathrm{LD}>\mathrm{Ck})$. Variations regarding osmolytes accumulation were also apparent among maize hybrids; the maximum accumulations were recorded in Dong Dan 80 followed by Wan Dan 13 and Run Nong 35, which indicated that Dong Dan 80 may perform better under water deficit conditions (Figures 2A-F).

\section{Activities of Enzymatic Antioxidants in Maize Hybrids under Drought Stress}

Responses of enzymatic antioxidants varied significantly $(P<0.05)$ under the influence of drought stress. Compared with well-watered control, activities of SOD in Don Dang 80 and Wan Dan 13 were significantly increased with the severity of drought stress; the maximum values were recorded at SD stress ( $40 \%$ FC). However, the activities of SOD in Run Nong 35 were dramatically reduced at SD stress, and the maximum values for SOD were recorded at LD stress level (80\% FC) (Figure 3A). The maximum activities of POD and CAT in Don Dang 80 and Wan Dan 13 were recorded at MRD stress (60\% FC), While in Run Nong 35, POD and CAT activities were maximum in well-watered control and LD stress ( $80 \%$ FC), respectively. The activities of POD and CAT varied among maize hybrids and followed the trend of Don Dang $80>$ Wan Dan $13>$ Run Nong 35 (Figures 3B,C). Moreover, patterns of APX, MDHAR, and DHAR activities were parallel to drought stress level (except APX in Run Nong 35), generally showing a linear increase with an increase in drought stress level. Activities of APX, MDHAR, and DHAR were increased by 24, 13, and 29\% in Don Dang 80 and 16, 11, and 10\% in Wan Dan 13 under SD conditions (40\% FC), respectively. Contrarily, for Run Nong 35, activities of these three antioxidants were declined at SD; the maximum APX 
TABLE 1 | Agronomic traits of three maize hybrids as influenced by different drought stress levels.

\begin{tabular}{|c|c|c|c|c|c|c|}
\hline Maize hybrids & Treatments & Plant height (cm) & Leaf area $\left(\mathrm{cm}^{2}\right)$ & $\begin{array}{c}\text { Shoot fresh } \\
\text { weight/plant (g) }\end{array}$ & $\begin{array}{c}\text { Shoot dry } \\
\text { weight/plant (g) }\end{array}$ & $\begin{array}{l}\text { Number of } \\
\text { leaves/plant }\end{array}$ \\
\hline \multirow[t]{5}{*}{ Dong Dan 80} & $\mathrm{Ck}$ & $202.45 \pm 3.76^{a}$ & $245.56 \pm 2.32^{a}$ & $275.01 \pm 6.34^{a}$ & $72.54 \pm 2.06^{a}$ & $14.88 \pm 0.33^{a}$ \\
\hline & LD & $201.87 \pm 4.56^{a}$ & $243.04 \pm 3.23^{a}$ & $267.23 \pm 6.43^{a b}$ & $68.67 \pm 2.05^{\mathrm{a}}$ & $14.68 \pm 0.32^{a b}$ \\
\hline & MRD & $198.67 \pm 3.78^{a}$ & $240.43 \pm 3.76^{\mathrm{ab}}$ & $260.89 \pm 4.89^{b}$ & $67.34 \pm 2.34^{a}$ & $14.22 \pm 0.23^{b}$ \\
\hline & $\mathrm{SD}$ & $195.45 \pm 5.98^{a}$ & $237.23 \pm 1.45^{\mathrm{b}}$ & $251.87 \pm 1.45^{b}$ & $62.78 \pm 1.15^{\mathrm{b}}$ & $13.87 \pm 0.16^{b}$ \\
\hline & Means & 199.61 & 241.565 & 263.75 & 67.83 & 14.41 \\
\hline \multirow[t]{5}{*}{ Wan Dan 13} & Ck & $201.65 \pm 1.89^{a}$ & $244.94 \pm 2.21^{a}$ & $272.67 \pm 4.78^{a}$ & $72.78 \pm 1.32^{\mathrm{a}}$ & $14.34 \pm 0.19^{a}$ \\
\hline & LD & $199.34 \pm 5.87^{a b}$ & $241.32 \pm 2.54^{\mathrm{ab}}$ & $265.4 \pm 5.54^{a b}$ & $65.87 \pm 0.99^{b}$ & $14.21 \pm 0.21^{a}$ \\
\hline & MRD & $196.56 \pm 2.89^{b}$ & $236.06 \pm 3.12^{\mathrm{b}}$ & $257.67 \pm 5.11^{b}$ & $64.67 \pm 1.77^{b c}$ & $13.67 \pm 0.21^{\mathrm{b}}$ \\
\hline & $\mathrm{SD}$ & $192.89 \pm 4.78^{b}$ & $230.67 \pm 2.76^{b}$ & $247.67 \pm 2.76^{b}$ & $60.67 \pm 1.78^{c}$ & $12.78 \pm 0.31^{\mathrm{C}}$ \\
\hline & Means & 197.61 & 238.25 & 260.85 & 66.00 & 13.75 \\
\hline \multirow[t]{5}{*}{ Run Nong 35} & $\mathrm{Ck}$ & $201.65 \pm 2.22^{a}$ & $243.66 \pm 2.65^{a}$ & $273.56 \pm 5.21^{a}$ & $71.45 \pm 1.57^{\mathrm{a}}$ & $13.89 \pm 0.14^{a}$ \\
\hline & LD & $198.65 \pm 3.54^{a}$ & $237.11 \pm 1.87^{b}$ & $263.34 \pm 4.81^{a}$ & $64.34 \pm 1.46^{b}$ & $13.11 \pm 0.13^{b}$ \\
\hline & MRD & $192.56 \pm 1.87^{b}$ & $230.23 \pm 2.87^{c}$ & $241.21 \pm 3.54^{b}$ & $58.89 \pm 0.88^{c}$ & $10.89 \pm 0.29^{c}$ \\
\hline & $\mathrm{SD}$ & $181.67 \pm 3.55^{\mathrm{C}}$ & $220.43 \pm 3.23^{d}$ & $224.98 \pm 3.23^{c}$ & $49.98 \pm 0.67^{d}$ & $9.54 \pm 0.14^{d}$ \\
\hline & Means & 193.63 & 232.86 & 250.77 & 61.17 & 11.86 \\
\hline
\end{tabular}

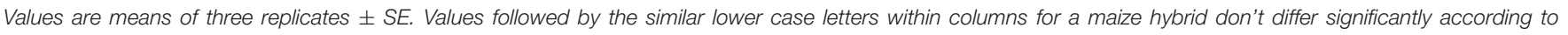

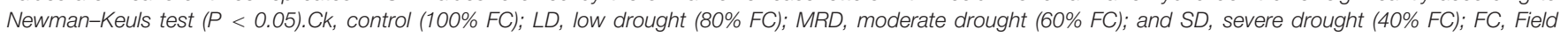
capacity.

TABLE 2 | Yield and related characteristics of three maize hybrids as influenced by different drought stress levels.

\begin{tabular}{|c|c|c|c|c|c|c|c|}
\hline Maize cultivars & Treatments & Ears/plant & Kernel rows/ear & Kernels/ear & $\begin{array}{l}\text { 100-kernel } \\
\text { weight (g) }\end{array}$ & $\begin{array}{c}\text { Grain } \\
\text { yield/plant }(\mathrm{g})\end{array}$ & $\begin{array}{c}\text { Biological } \\
\text { yield/plant (g) }\end{array}$ \\
\hline \multirow[t]{5}{*}{ Dong Dan 80} & Ck & $1.22 \pm 0.02^{\mathrm{a}}$ & $14.78 \pm 0.24^{\mathrm{a}}$ & $472.35 \pm 3.43^{a}$ & $23.98 \pm 0.22^{a}$ & $138.56 \pm 0.89^{a}$ & $331.77 \pm 3.34^{a}$ \\
\hline & LD & $1.20 \pm 0.06^{a}$ & $14.68 \pm 0.19^{a}$ & $469.46 \pm 5.76^{a}$ & $23.09 \pm 0.65^{a b}$ & $129.21 \pm 1.67^{b}$ & $329.78 \pm 4.23^{\circ}$ \\
\hline & MRD & $1.19 \pm 0.09^{a}$ & $14.04 \pm 0.38^{b}$ & $466.13 \pm 4.34^{a}$ & $22.78 \pm 0.22^{b}$ & $126.45 \pm 1.67^{b}$ & $319.78 \pm 3.76^{b}$ \\
\hline & $\mathrm{SD}$ & $1.15 \pm 0.06^{a}$ & $13.65 \pm 0.41^{b}$ & $459.26 \pm 2.87^{b}$ & $21.56 \pm 0.25^{c}$ & $119.65 \pm 0.98^{c}$ & $310.56 \pm 4.87^{\circ}$ \\
\hline & Means & 1.19 & 14.29 & 466.80 & 22.85 & 128.47 .22 & 322.97 \\
\hline \multirow[t]{5}{*}{ Wan Dan 13} & Ck & $1.21 \pm 0.05^{\mathrm{a}}$ & $14.21 \pm 0.31^{a}$ & $474.10 \pm 2.87^{a}$ & $22.87 \pm 0.35^{a}$ & $134.67 \pm 1.21^{a}$ & $327.99 \pm 2.65^{a}$ \\
\hline & LD & $1.19 \pm 0.08^{a}$ & $14.08 \pm 0.23^{a}$ & $465.90 \pm 2.78^{b}$ & $21.78 \pm 0.34^{b}$ & $126.76 \pm 0.76^{b}$ & $324.76 \pm 2.86^{a}$ \\
\hline & MRD & $1.17 \pm 0.05^{a}$ & $13.67 \pm 0.16^{b}$ & $459.06 \pm 4.76^{b}$ & $20.67 \pm 0.35^{c}$ & $118.65 \pm 1.21^{\mathrm{c}}$ & $315.67 \pm 5.87^{b}$ \\
\hline & $\mathrm{SD}$ & $1.13 \pm 0.08^{a}$ & $12.32 \pm 0.32^{\mathrm{C}}$ & $447.14 \pm 6.09^{c}$ & $19.65 \pm 0.21^{d}$ & $104.34 \pm 1.55^{d}$ & $303.89 \pm 3.76^{\circ}$ \\
\hline & Means & 1.18 & 13.57 & 461.55 & 21.24 & 121.11 & 318.08 \\
\hline \multirow[t]{5}{*}{ Run Nong 35} & $\mathrm{Ck}$ & $1.21 \pm 0.03^{\mathrm{a}}$ & $14.08 \pm 0.32^{a}$ & $471.44 \pm 2.87^{a}$ & $23.07 \pm 0.13^{a}$ & $133.76 \pm 1.34^{a}$ & $328.67 \pm 4.11^{a}$ \\
\hline & LD & $1.17 \pm 0.05^{a b}$ & $13.79 \pm 0.21^{a}$ & $456.33 \pm 4.33^{b}$ & $21.11 \pm 0.21^{b}$ & $116.11 \pm 1.22^{b}$ & $315.67 \pm 3.76^{b}$ \\
\hline & MRD & $1.14 \pm 0.04^{\mathrm{ab}}$ & $11.67 \pm 0.26^{b}$ & $423.47 \pm 2.67^{\mathrm{C}}$ & $19.55 \pm 0.18^{c}$ & $93.65 \pm 1.79^{\mathrm{c}}$ & $303.78 \pm 6.12^{c}$ \\
\hline & $\mathrm{SD}$ & $1.10 \pm 0.03^{b}$ & $9.67 \pm 0.21^{c}$ & $380.12 \pm 3.65^{d}$ & $17.45 \pm 0.22^{d}$ & $76.12 \pm 1.11^{d}$ & $274.27 \pm 4.21^{\circ}$ \\
\hline & Means & 1.16 & 12.30 & 432.84 & 20.30 s & 104.91 & 305.60 \\
\hline
\end{tabular}

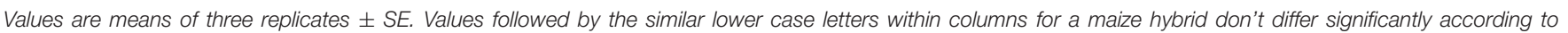

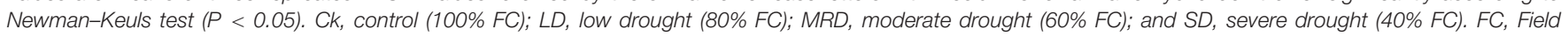
capacity.

activity was observed at $\mathrm{LD}$, while the maximum MDHAR and DHAR activities were recorded at MRD level (Figures 3D-F). Overall, Don Dang 80 showed greater activities of enzymatic antioxidants compared with Wan Dan 13 or Run Nong 35 (Figures 3A-F).

\section{Levels of Non-enzymatic Antioxidants in Maize Hybrids under Drought Stress}

Drought stress induced the changes in non-enzymatic antioxidants which led to different responses of three maize hybrids to water deficit conditions. Moderate and SD stress
(60 and 40\% FC) resulted in significantly higher AsA and DHA contents in all the maize hybrids. GSH contents were generally unaffected by drought stress in all maize hybrids except for Dong Dan 80, where GSH contents were significantly increased at $40 \%$ FC. Drought stress at any levels significantly increased the GSSG contents in Dong Dan 80, while did not significantly alter the GSSG in Run Nong 35. In Wan Dan 13, GSSG contents were only increased at SD stress to a significant level. Averaged across different drought stress levels, Dong Dan 80 and Run Nong 35 showed the maximum and minimum levels of non-enzymatic antioxidants, respectively (Figures 4A-H). 

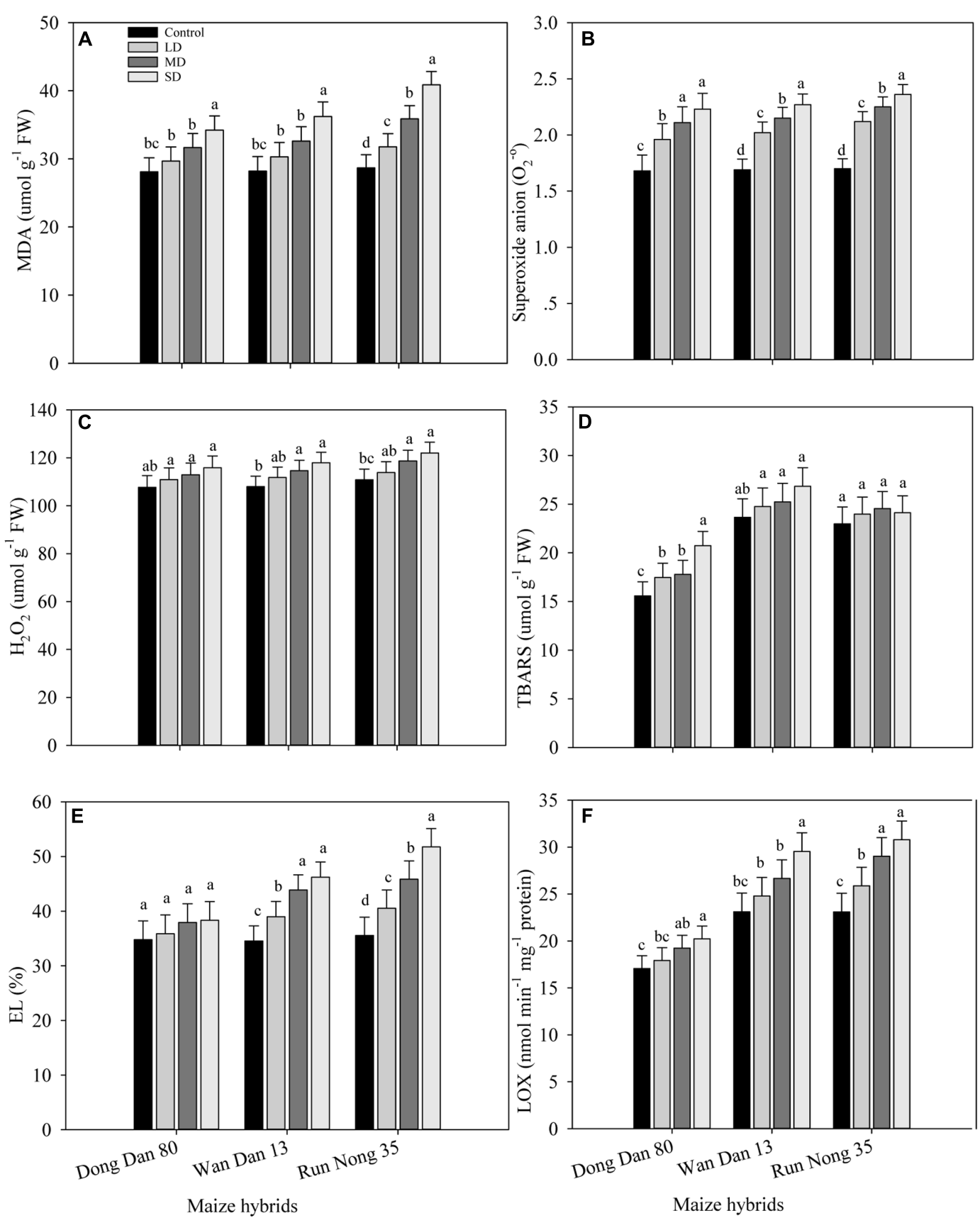

FIGURE 1 | Influence of different drought stress levels on the production of (A) malenoaldehyde (MDA), (B) superoxide anion ( $\left.\mathrm{O}_{2} \cdot{ }^{-}\right)$, (C) hydrogen peroxide $\left(\mathrm{H}_{2} \mathrm{O}_{2}\right)$, (D) thiobarbituric acid reactive substances (TBARS), (E) electrolyte leakage (EL), and (F) lipoxygenase (LOX) in three maize hybrids. Capped bars above means represent $\pm \mathrm{SE}$ of three replicates. Small alphabetical letters above means denote the significant differences among treatment with in a maize hybrid at $P \leq 0.05$. Ck, control (100\% FC); LD, low drought (80\% FC); MRD, moderate drought (60\% FC); and SD, severe drought (40\% FC); FC, Field capacity.

\section{DISCUSSION}

Drought is one of the major constraints for higher growth and productivity of field crops. Drought-induced adversities in plants demands the studies on exploring the drought tolerance mechanisms in plants to overcome significant yield losses under water stress (Singh et al., 2014, 2015). In this study, we accessed the osmolyte accumulation, antioxidant defense system and ROS-based variations in growth and yield performance of maize under drought stress. Drought stress severely inhibited growth, yield and related characteristics of maize, however, all three maize hybrids showed different responses in this regard. A decreasing trend was observed regarding maize performance with increase in drought stress 

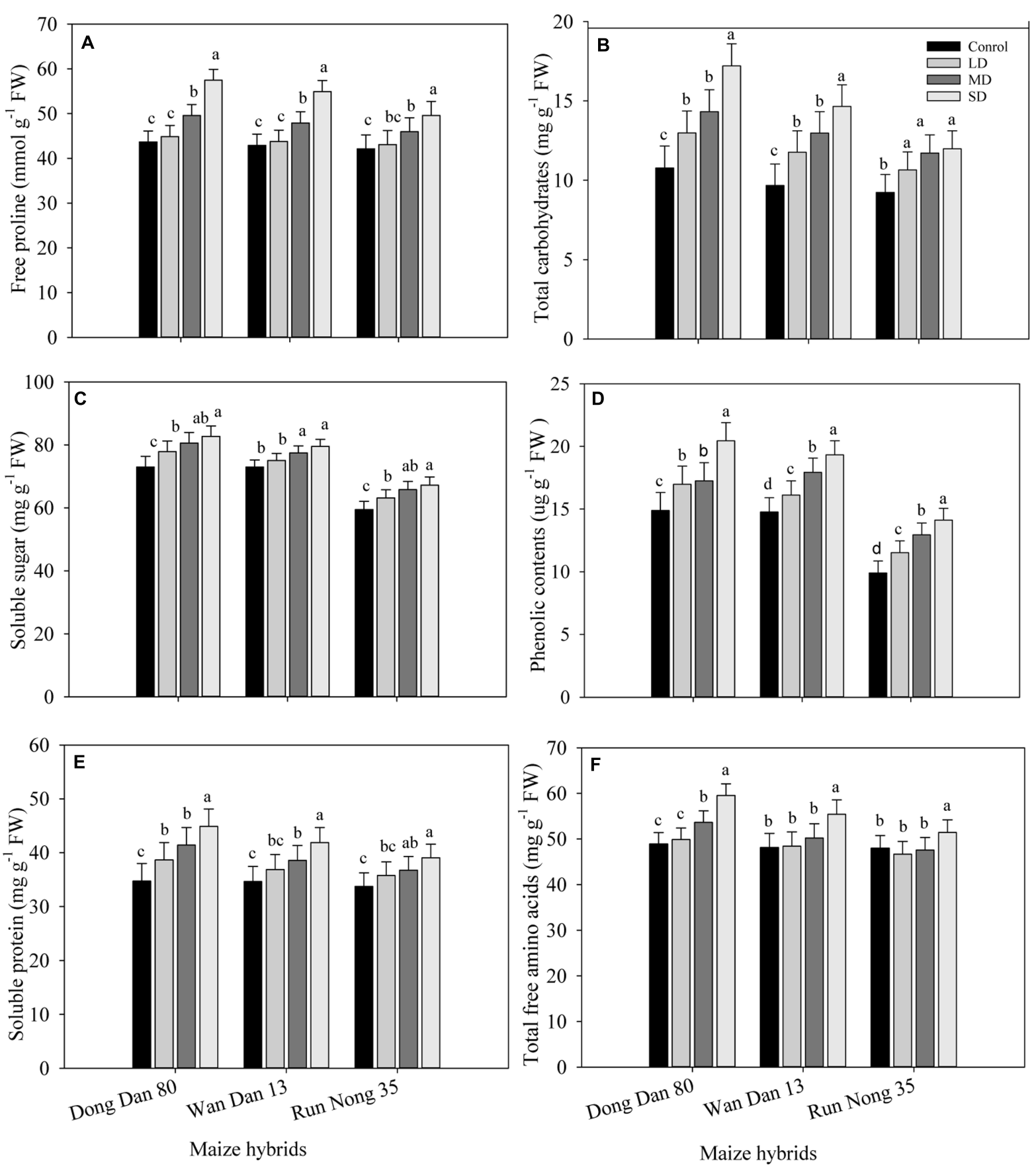

FIGURE 2 | Influence of different drought stress levels on the accumulations of (A) free proline, (B) total carbohydrates, (C) soluble sugars, (D) phenolic contents, (E) soluble protein, and (F) total free amino acids in three maize hybrids. Capped bars above means represent \pm SE of three replicates. Small alphabetical letters above means denote the significant differences among treatment with in a maize hybrid at $P \leq 0.05$. Ck, control (100\% FC); LD, low drought (80\% FC); MRD, moderate drought (60\% FC); and SD, severe drought (40\% FC); FC, Field capacity.

levels, nonetheless, such drought-induced adversities were more prominent in Run Nong 35 than Dong Dan 80 or Wan Dan 13 (Tables 1 and 2). Previously in Chickpea, Mafakheri et al. (2010) noted reduced growth and severe yield losses when drought was imposed at reproductive stages. Moreover, $\mathrm{Ge}$ et al. (2012) also reported the reduced nutrient uptake, biomass accumulation and harvest index in maize under drought stress.

In the present study, ROS accumulation and membrane damage seemed to be higher under drought stress in all maize hybrids; however, effects were more apparent in Run Nong 35 which might be due to its sensitivity to drought 

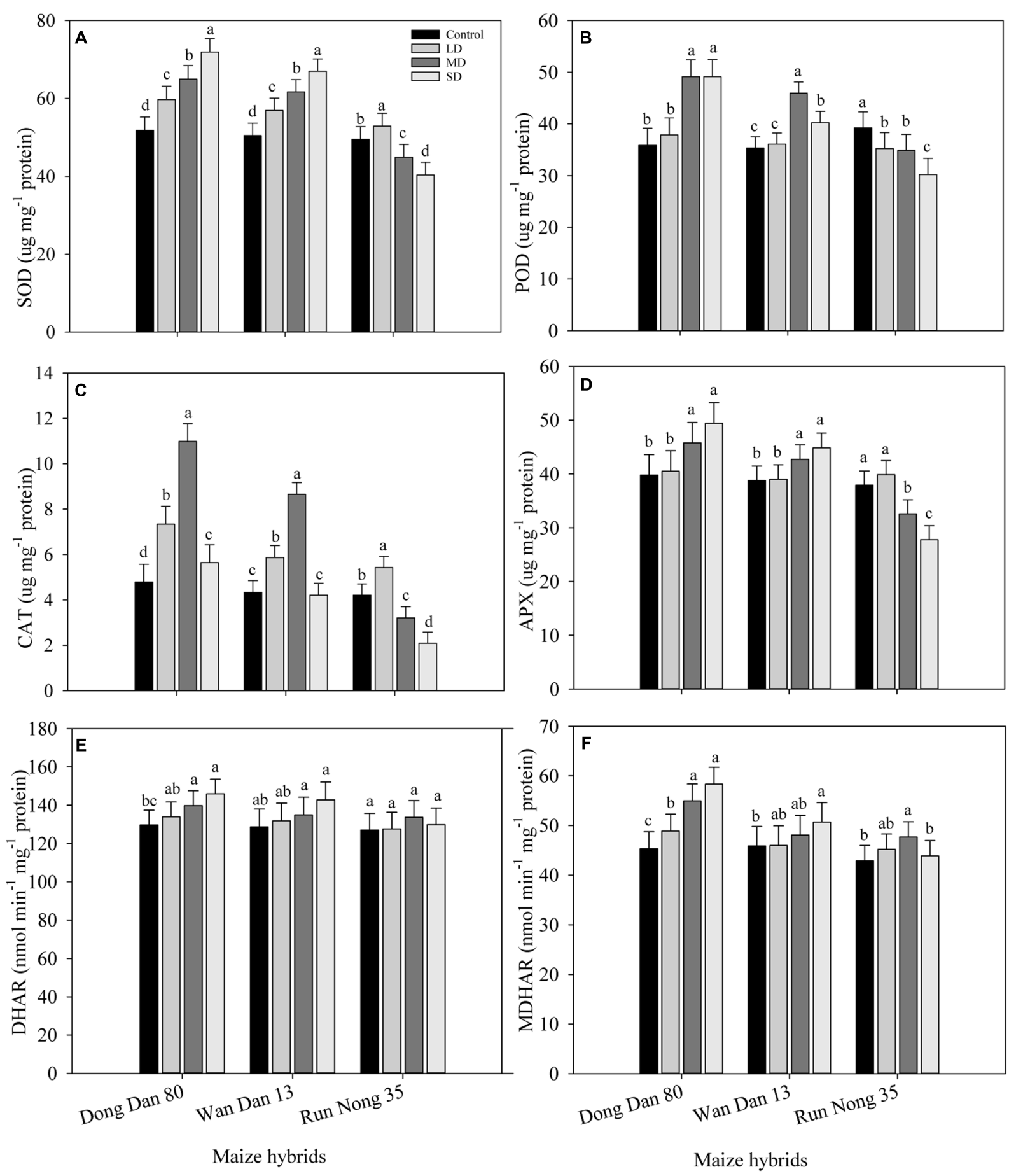

FIGURE 3 | Influence of different drought stress levels on the activities of (A) superoxide dismutase (SOD), (B) peroxidase (POD), (C) catalase (CAT), (D) Ascorbate peroxidase (APX), (E) Dehydroascorbater eductase (DHAR), and (F) monodehydroascorbater eductase (MDHAR) in three maize hybrids. Capped bars above means represent \pm SE of three replicates. Small alphabetical letters above means denote the significant differences among treatment with in a maize hybrid at $P \leq 0.05$. Ck, control (100\% FC); LD, low drought (80\% FC); MRD, moderate drought (60\% FC); and SD, severe drought (40\% FC); FC, Field capacity.

stress (Figures 1A-F). Synthesis and accumulation of ROS is exaggerated under stressed conditions and aggressively damages the biological membranes and organic molecules. Moreover, enhanced lipid peroxidation in terms of MDA accumulation serves as an index of oxidative damage caused by ROS. Recently, Yanling et al. (2015) reported that enhanced anti-oxidant activities to quench ROS were related to drought tolerance in Chinese domesticated water melons (C. lanatus var. lanatus). 

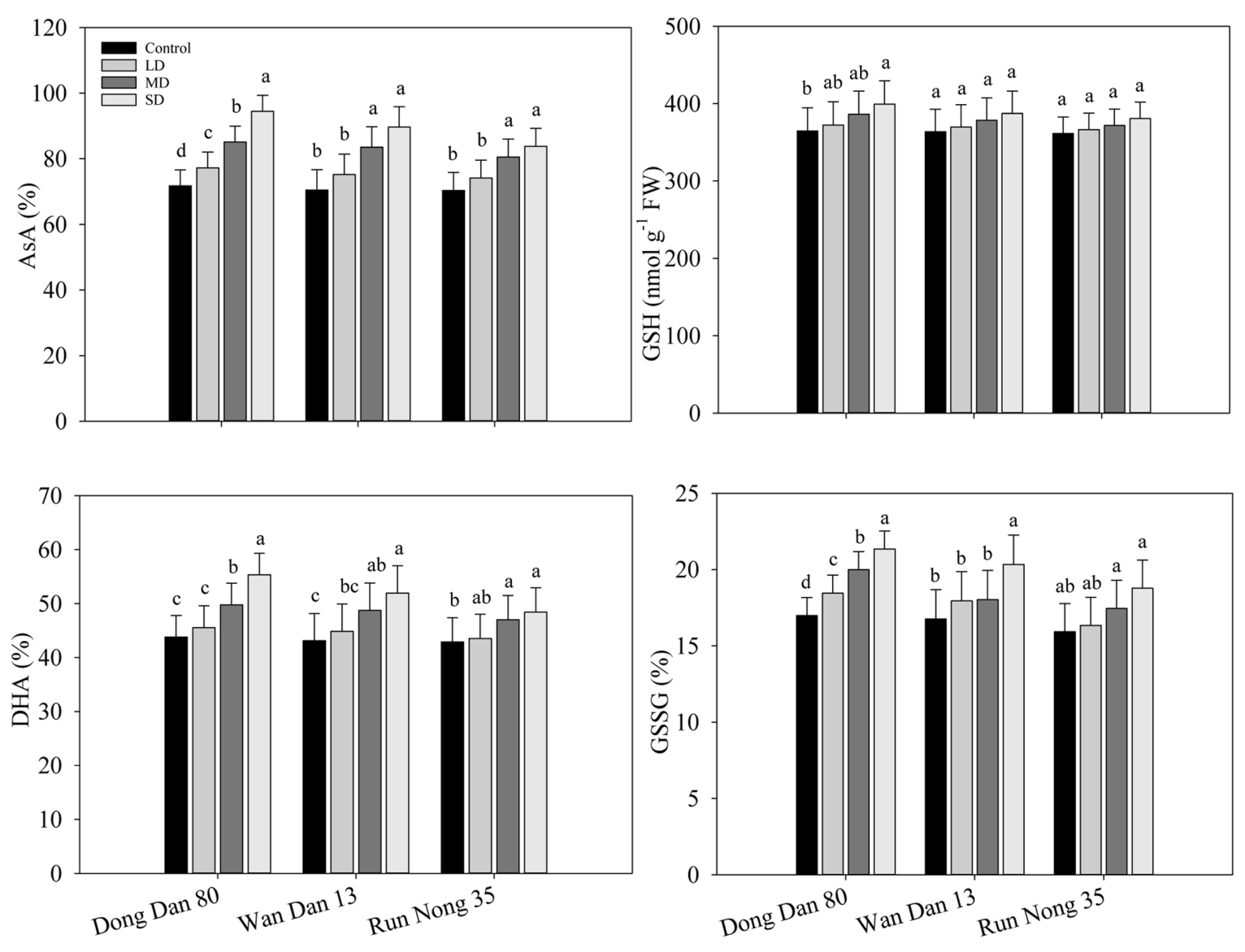

Maize hybrids

Maize hybrids

FIGURE 4 | Influence of different drought stress levels on (A) ascorbic acid (AsA), (B) reduced glutathione (GSH), (C) dehydroascorbate (DHA), (D) oxidized glutathione (GSSG) in three maize hybrids. Small alphabetical letters above means denote the significant differences among treatment with in a maize hybrid at $P \leq 0.05$. Capped bars above means represent \pm SE of three replicates. Ck, control (100\% FC); LD, low drought (80\% FC); MRD, moderate drought (60\% FC); and SD, severe drought (40\% FC); FC, Field capacity.

Furthermore, drought stress caused an increase in EL compared to well-watered conditions in Cassia occidentalis (Srivastava and Srivastava, 2015). The drought tolerance in young oil palm plants was related to efficient protective mechanisms against ROS by activating enzymatic and non-enzymatic antioxidant strategies simultaneously (Silva et al., 2015).

Drought stress triggered the production and accumulation of different osmolytes in all maize hybrids. Concentrations of proline, carbohydrates, SS, phenolic contents, proteins, and TFA were considerably higher in all maize hybrids under SD conditions as compared to control; however, Dong Dan 80 accumulated more osmolytes than Wan Dan 13 or Run Nong 35 (Figures 2A-F). Accumulation of different compatible solutes and their involvement in osmotic adjustment, maintenance of cell turgor and protection of different cell structures might lead to significant improvement in drought tolerance in maize. It has been observed that moderate to SD affects the biosynthesis and accumulation of proline and soluble carbohydrates (Ghaderi and Siosemardeh, 2011).
A significant increase in carbohydrate metabolites especially sugars and starches indicated a diurnal turnover under limited water supply in Phoebe zhennan plants, suggesting their availability to be metabolized in source organs or their translocation toward roots ( $\mathrm{Hu}$ et al., 2015). The accumulation of some compatible solutes, i.e., proline and other free amino acids increased significantly in Salicornia brachiata under PEG-induced water stress that played dynamic roles in osmotic regulation, $\mathrm{pH}$ maintenance, protection of cellular macromolecules, and scavenging of free radicals to negate water stress (Parida and Jha, 2013). SD up-regulates the concentrations of free amino acids and SS that might be due to increased proteolysis under water-deficit conditions (Good and Maclagan, 1993; Alizadeh et al., 2011). The significant accumulation of phenolic compounds in tissues of drought tolerant plants and their powerful ROS scavenging roles indicate their roles against the oxidative damage caused by drought and salt stress (Reginato et al., 2015). Some previous reports also confirmed the contributions of different osmolytes in inducing drought 
tolerance in various crops (Tan et al., 2006; Farooq et al., 2009; Pawar et al., 2015).

In the present study, drought stress up-regulated the activities of anti-oxidative defense systems in all maize hybrids. Results showed that drought stress stimulated the enzymatic antioxidative defense system; however, activities of some antioxidants such as POD and CAT were reduced with severity of drought. Furthermore, all maize hybrids showed a variable response to drought stress, the activities of all antioxidants were generally higher in Dong Dan 80 than Wan Dan 13 or Run Nong 35. The enzymatic activities in Run Nong 35 were increased at initial drought levels but decreased dramatically at SD levels, exhibiting drought sensitive behavior of Run Nong 35 (Figures 3A-F).

The contents of AsA, GSH, GSSG, DHA and their combined concentrations were higher at higher levels of drought; the concentrations of these non-enzymatic antioxidants were higher in Dong Dan 80 than those in Wan Dan 13 or Run Nong 35. Drought stress induced changes in non-enzymatic antioxidants that led to different responses of three maize hybrids to water deficit conditions (Figures 4A-H). Previous studies proved that higher activities/levels of enzymatic and non-enzymatic antioxidants are important to induce drought tolerance. For example, a better anti-oxidative defense system may provide protection against oxidative stress and enhance plant tolerance under drought conditions. A key role of antioxidants in drought tolerance has also been reported in various crops including rice (Yang et al., 2014), sugarcane (Sales et al., 2015), and wheat (Kaur and Zhawar, 2015). Furthermore, enzymes involved in the ascorbate-glutathione cycle, i.e., APX, DHAR, and MDHAR are also important to enhance drought tolerance of a plant by quenching superoxide radicals and $\mathrm{H}_{2} \mathrm{O}_{2}$ (Fazeli et al., 2007). The AsA, GSH, $\alpha$-tocopherol and carotenoids might be good indicators for drought stress tolerance (Guha et al., 2012). In this study, involvement of AsA against ROS formation under drought stress cannot be ignored; however, on the other hand, glutathione metabolism and pools of GSH are directly or indirectly related

\section{REFERENCES}

Adebayo, M., and Menkir, A. (2015). Assessment of hybrids of drought tolerant maize (Zea mays L.) inbred lines for grain yield and other traits under stress managed conditions. Nigerian J. Genet. 28, 19-23. doi: 10.1016/j.nigjg.2015. 06.004

Ainsworth, E. A., and Gillespie, K. M. (2007). Estimation of total phenolic content and other oxidation substrates in plant tissues using Folin-Ciocalteu reagent. Nat. Prot. 2, 875-877. doi: 10.1038/nprot.2007.102

Alizadeh, A., Alizade, V., Nassery, L., and Eivazi, A. (2011). Effect of drought stress on apple dwarf root stocks. J. Appl. Sci. Eng. Technol. 13, 86-94.

Anderson, M. E. (1985). Determination of glutathione and glutathione disulphides in biological samples. Methods Enzymol. 113, 548-555. doi: 10.1016/S00766879(85)13073-9

Anjum, N. A., Sofo, A., Scopa, A., Roychoudhury, A., Gill, S. S., Iqbal, M., et al. (2014). Lipids and proteins-major targets of oxidative modifications in abiotic stressed plants. Environ. Sci. Pollut. Res. 2, 4099-4121. doi: 10.1007/s11356014-3917-1

Anjum, S. A., Farooq, M., Wang, L. C., Xue, L. L., Wang, S. G., Wang, L., et al. (2011a). Gas exchange and chlorophyll synthesis of maize cultivars are to the responses of plants against various environmental stresses (Foyer et al., 2001). Higher GSH concentration, particularly GSSG/GSH ratios in Dong Dan 80 might be associated with low $\mathrm{H}_{2} \mathrm{O}_{2}$ concentrations. It might be assumed that maize plants depend on constitutive GSH to counteract the drought-related oxidative stress, where enhanced non-enzymatic functioning in Dong Dan 80 enhanced its ability to withstand the drought stress. Our results corroborate those of Zhang et al. (2013) who demonstrated that drought stress exacerbated the production and accumulation of non-enzymatic antioxidants in drought tolerant Canna edulis.

In summary, maize growth and yield responses were related to ROS production, osmolyte accumulation and activation of antioxidative defense system under drought conditions. Dong Dan 80 performed better with minimum yield losses and proved drought tolerant with enhanced osmolyte accumulation, and efficient enzymatic and non-enzymatic anti-oxidative defense systems even at SD stress conditions than Wan Dan 13 or Run Nong 35. In future, physiological and biochemical indices-based selection of drought tolerant germplasm may be helpful to develop novel drought-resistant genotypes that can be successfully cultivated in field conditions even at limited water supply.

\section{AUTHOR CONTRIBUTIONS}

SA and UA conducted experiment, MT, IK, SH, BS, and AZ assisted in data analyzing and manuscript write up, FA, IA, and MS assisted in write up and English improvement. LW supervised the study.

\section{ACKNOWLEDGMENT}

Funding provided by National Science Foundation (No. 31271673) and Special Fund for Agro-Scientific Research in the Public Interest (No. 201503127) is highly acknowledged.

enhanced by exogenously-applied glycinebetaine under drought conditions. Plant Soil Environ. 577, 326-331.

Anjum, S. A., Wang, L. C., Farooq, M., Hussain, M., Xue, L. L., and Zou, C. M. (2011b). Brassinolide application improves the drought tolerance in maize through modulation of enzymatic antioxidants and leaf gas exchange. J. Agron. Crop Sci. 197, 177-185. doi: 10.1111/j.1439-037X.2010.00459.x

Anjum, S. A., Wang, L. C., Farooq, M., Xue, L. L., and Ali, S. (2011c). Fulvic acid application improves the maize performance under well-watered and drought conditions. J. Agron. Crop Sci. 197, 409-417. doi: 10.1111/j.1439-037X.2011. 00483.x

Ashraf, M., and Foolad, M. R. (2007). Roles of glycine betaine and proline in improving plant abiotic stress resistance. Environ. Exp. Bot. 59, 206-216. doi: 10.1016/j.envexpbot.2005.12.006

Ashraf, U., Kanu, A. S., Mo, Z., Hussain, S., Anjum, S. A., Khan, I., et al. (2015). Lead toxicity in rice: effects, mechanisms, and mitigation strategies-a mini review. Environ. Sci. Pollut. Res. 22, 18318-18332. doi: 10.1007/s11356-0155463-X

Ashraf, U., Salim, M. N., Sher, A., Sabir, S. R., Khan, A., Pan, S. G., et al. (2016). Maize growth, yield formation and water-nitrogen usage in response to varied irrigation and nitrogen supply under semi-arid climate. Turk. J. Field Crops 21, 87-95. doi: 10.17557/tjfc.93898 
Bates, L. S., Waldren, R. P., and Teare, I. D. (1973). Rapid determination of free proline for water-stress studies. Plant Soil 39, 205-207. doi: 10.1016/j.dental. 2010.07.006

Bradford, M. N. (1976). A rapid and sensitive method for the quantitation of microgram quantities of protein utilizing the principle of protein-dye binding. Anal. Chem. 72, 248-254.

Cakmak, I., and Horst, J. H. (1991). Effects of aluminum on lipid peroxidation, superoxide dismutase, catalase, and peroxidase activities in root tips of soybean (Glycine max). Physiol. Plant. 83, 463-468. doi: 10.1111/j.1399-3054.1991. tb00121.x

Critchley, W., and Klaus, S. (1991). A Manual for the Design and Construction of Water Harvesting Schemes for Plant Production. Available at: http://www.fao. org/docrep/u3160e/4316eo4.htm [accessed April 14, 2009].

Dhindsa, R. S., Plumb-Dhindsa, P., and Thorpe, T. A. (1981). Leaf senescence: correlated with increased levels of membrane permeability and lipid peroxidation, and decreased levels of superoxide dismutase and catalase. J. Exp. Bot. 32, 93-101. doi: 10.1093/jxb/32.1.93

Doulis, A. G., Debian, N., Kingston-Smith, A. H., and Foyer, C. H. (1997). Differential localization of antioxidants in maize leaves. Plant Physiol. 114, 1031-1037. doi: 10.1104/pp.114.3.1031

Dubois, M., Gilles, K. A., Hamil, J. K., Rebers, P. A., and Smith, F. (1956). Colorimetric method for determination of sugars and related substances. Anal. Chem. 28, 350-356. doi: 10.1021/ac60111a017

Elstner, F. F., and Heupel, C. (1976). Inhibition of nitrite formation from hydroxyl ammonium chloride: a simple assay for superoxide dismutase. Anal. Biochem. 70, 616-620. doi: 10.1016/0003-2697(76)90488-7

Fales, F. W. (1951). The assimilation and degradation of carbohydrates by yeast cells. J. Biol. Chem. 193, 113-124.

Farooq, M., Wahid, A., Kobayashi, N., Fujita, D., and Basra, S. M. A. (2009). Plant drought stress: effects, mechanisms and management. Agron. Sust. Dev. 29, 185-212. doi: 10.1051/agro:2008021

Fazeli, F., Ghorbanli, M., and Niknam, V. (2007). Effect of drought on biomass, protein content, lipid peroxidation and antioxidant enzymes in two sesame cultivars. Biol. Plant. 51, 98-103. doi: 10.1007/s10535-007-0020-1

Foyer, C. H., Dujardyn, M., and Lemoine, Y. (1989). Responses of photosynthesis and the xanthophyll and ascorbate-glutathione cycle to changes in irradiances, photoinhibition and recovery. Plant Physiol. Biochem. 27, $751-760$.

Foyer, C. H., Theodoulou, F. L., and Delrot, S. (2001). The functions of interand intracellular glutathione transport systems in plants. Trends Plant Sci. 6, 486-492. doi: 10.1016/S1360-1385(01)02086-6

Gale, F., Jewison, M., and Hansen, J. (2014). Prospects for China's Corn Yield Growth and Imports. Washington, DC: Department of Agriculture Economic Research Service.

Ge, T. D., Sun, N. B., Bai, L. P., Tong, C. L., and Sui, F. G. (2012). Effects of drought stress on phosphorus and potassium uptake dynamics in summer maize (Zea mays) throughout the growth cycle. Acta Physiol. Plant. 34, 2179-2186. doi: 10.1007/s11738-011-0901-y

Ghaderi, N., and Siosemardeh, A. (2011). Response to drought stress of two strawberry cultivars (cv. Kurdistan and Selva). Hortic. Environ. Biotechnol. 52, 6-12. doi: 10.1007/s13580-011-0019-6

Good, A. G., and Maclagan, J. L. (1993). Effects of drought stress on the water relations in Brassica species. Can. J. Plant Sci. 73, 525-529. doi: 10.4141/ cjps93-071

Guha, A., Sengupta, D., Rasineni, G. K., and Reddy, A. R. (2012). Nonenzymatic antioxidative defence in drought-stressed mulberry (Morus indica L.) genotypes. Trees 26, 903-918. doi: 10.1007/s00468-011-0665-4

Hodges, D. M., Andrews, C. J., Johnson, D. A., and Hamilton, R. I. (1996). Antioxidant compound responses to chilling stress in differentially sensitive inbred maize lines. Physiol. Plant. 98, 685-692. doi: 10.1111/j.1399-3054.1996. tb06672.x

Hu, Y., Wang, B., Hu, T., Chen, H., Li, H., Zhang, W., et al. (2015). Combined action of an antioxidant defence system and osmolytes on drought tolerance and post-drought recovery of Phoebe zhennan S. Lee saplings. Acta Physiol. Plant. 37, 1-13. doi: 10.1007/s11738-015-1831-x

Huang, S., Wu, Y. N., and Liu, M. (2010). Quantitative determination of total freeamino acid in Nervilia fordii (Hance) Schltr. by ninhydrin colorimetric method. Chin. J. Inform. Tradit. Chin. Med. 17, 50-52.
Kaur, L., and Zhawar, V. K. (2015). Phenolic parameters under exogenous ABA, water stress, salt stress in two wheat cultivars varying in drought tolerance. Indian J. Plant Physiol. 20, 151-156. doi: 10.1007/s40502-0150156-5

Lutts, S., Kinet, J. M., and Bouharmont, J. (1996). NaCl-induced senescence in leaves of rice (Oryza sativa L.) cultivars differing in salinity resistance. Anal. Bot. 78, 389-398. doi: 10.1006/anbo.1996.0134

Mafakheri, A., Siosemardeh, A., Bahramnejad, B., Struik, P. C., and Sohrabi, Y. (2010). Effect of drought stress on yield, proline and chlorophyll contents in three chickpea cultivars. Aust. J. Crop Sci. 4, 580-585.

Maksup, S., Roytrakul, S., and Supaibulwatana, K. (2014). Physiological and comparative proteomic analyses of Thai jasmine rice and two check cultivars in response to drought stress. J. Plant Interact. 9, 43-55. doi: 10.1080/17429145. 2012.752042

Minguez-Mosquera, M. I., Jaren-Galen, M., and Garrido-Fernaández, J. (1993). Lipoxygenase activity during pepper ripening and processing of paprika. Phytochemistry 32, 1103-1108. doi: 10.1016/S0031-9422(00)95073-8

Mukherjee, S. P., and Choudhuri, M. A. (1983). Implications of water stressinduced changes in the levels of endogenous ascorbic acid and hydrogen peroxide in Vigna radiata seedlings. Physiol. Plant. 58, 166-170. doi: 10.1111/ j.1399-3054.1983.tb04162.x

Munné-Bosch, S., and Penuelas, J. (2003). Photo and antioxidative protection, and a role for salicylic acid during drought and recovery in field grown Phillyrea angustifolia plants. Planta 217, 758-766. doi: 10.1007/s00425-003-1037-0

Nakano, Y., and Asada, K. (1981). Hydrogen peroxide is scavenged by ascorbate specific peroxidase in spinach chloroplasts. Plant Cell Physiol. 22, 867-880.

Parida, A. K., and Jha, B. (2013). Physiological and biochemical responses reveal the drought tolerance efficacy of the halophyte Salicornia brachiata. J. Plant Growth Regul. 32, 342-352. doi: 10.1007/s00344-012-9303-7

Pawar, V. V., Lokhande, P. K., Dalvi, U. S., Awari, V. R., Kale, A. A., Chimote, V. P., et al. (2015). Effect of osmotic stress on osmolyte accumulation and ammonia assimilating enzymes in chickpea cultivars. Indian J. Plant Physiol. 20, 276-280. doi: 10.1007/s40502-015-0159-2

Reginato, M., Varela, C., Cenzano, A., and Luna, V. (2015). "Role of polyphenols as antioxidants in native species from argentina under drought and salinization," in Reactive Oxygen Species and Oxidative Damage in Plants Under Stress, eds D. K. Gupta, J. M. Palma, F. José, and J. Corpas (New York, NY: Springer International Publishing), 247-267.

Saini, H. S., and Westgate, M. E. (2000). Reproductive development in grain crops during drought. Adv. Agron. 68, 59-96. doi: 10.1016/S0065-2113(08)60843-3

Sales, C. R. G., Marchiori, P. E. R., Machado, R. S., Fontenele, A. V., Machado, E. C., Silveira, J. A. G., et al. (2015). Photosynthetic and antioxidant responses to drought during the sugarcane ripening. Photosynthetica 53, 547-554. doi: 10.1007/s11099-015-0146-x

Sharma, P., Jha, A. B., Dubey, R. S., and Pessarakli, M. (2012). Reactive oxygen species, oxidative damage and antioxidative defense mechanism in plants under stressful conditions. J. Bot. 2012, 217037. doi: 10.1155/2012/217037

Silva, P. A. IV, Oliveira, V., Rodrigues, K. C., Cosme, V. S., Bastos, A. J., Detmann, K. S., et al. (2015). Leaf gas exchange and multiple enzymatic and nonenzymatic antioxidant strategies related to drought tolerance in two oil palm hybrids. Trees 30, 203-214. doi: 10.1007/s00468-015-1289-x

Singh, R., Mishra, A., Dhawan, S. S., Shirke, P. A., Gupta, M. M., and Sharma, A. (2015). Physiological performance, secondary metabolite and expression profiling of genes associated with drought tolerance in Withania somnifera. Protoplasma 252, 1439-1450.

Singh, R., Pandey, N., Naskar, J., and Shirke, P. A. (2014). Physiological performance and differential expression profiling of genes associated with drought tolerance in contrasting varieties of two Gossypium species. Protoplasma 252, 423-438. doi: 10.1007/s00709-014-0686-0

Srivastava, S., and Srivastava, M. (2015). Growth response and antioxidant enzyme activity of Cassia occidentalis exposed to soil moisture stress. Biolife 3, 519-523. doi: 10.17812/blj2015.32.24

Subbarao, G. V., Nam, N. H., Chauhan, Y. S., and Johansen, C. (2000). Osmotic adjustment, water relations and carbohydrate remobilization in pigeonpea under water deficits. J. Plant Physiol. 157, 651-659. doi: 10.1016/S01761617(00)80008-5

Taiz, L., and Zeiger, E. (2006). Plant Physiology, 4th Edn. Sunderland, MA: Sinauer Associates Inc. 
Tan, Y., Liang, Z., Shao, H., and Du, F. (2006). Effect of water deficits on the activity of anti-oxidative enzymes and osmoregulation among three different genotypes of Radix astragaliat seeding stage. Colloids Surf. B Biointerfaces 49, 59-64. doi: 10.1016/j.colsurfb.2006.02.014

Upadhyaya, A., Sankhla, D., Davis, T. D., Sankhla, N., and Smith, B. N. (1985). Effect of paclobutrazol on the activities of some enzymes of activated oxygen metabolism and lipid peroxidation in senescing soybean leaves. J. Plant Physiol. 121, 453-461. doi: 10.1016/S0176-1617(85) 80081-X

Xing, D., and Wu, Y. (2012). Photosynthetic response of three climber plant species to osmotic stress induced by polyethylene glycol (PEG) 6000. Acta Physiol. Plant. 34, 1659-1668. doi: 10.1007/s11738-012-0961-7

Yang, P. M., Huang, Q. C., Qin, G. Y., Zhao, S. P., and Zhou, J. G. (2014). Different drought-stress responses in photosynthesis and reactive oxygen metabolism between autotetraploid and diploid rice. Photosynthetica 52, 193-202. doi: 10. 1007/s11099-014-0020-2

Yanling, M., Yang, R., Liu, L., Gu, X., Yang, X., Wang, Y., et al. (2015). Growth, photosynthesis and adaptive responses of wild and domesticated watermelon genotypes to drought stress and subsequent re-watering. Plant Growth Regul. 79, 229-241. doi: 10.1007/s10725-015-0128-9

Zhang, W., Tian, Z., Pan, X., Zhao, X., and Wang, F. (2013). Oxidative stress and non-enzymatic antioxidants in leaves of three edible canna cultivars under drought stress. Hortic. Environ. Biotechnol. 54, 1-8. doi: 10.1007/s13580-0130070-6

Conflict of Interest Statement: The authors declare that the research was conducted in the absence of any commercial or financial relationships that could be construed as a potential conflict of interest.

Copyright (C) 2017 Anjum, Ashraf, Tanveer, Khan, Hussain, Shahzad, Zohaib, Abbas, Saleem, Ali and Wang. This is an open-access article distributed under the terms of the Creative Commons Attribution License (CC BY). The use, distribution or reproduction in other forums is permitted, provided the original author(s) or licensor are credited and that the original publication in this journal is cited, in accordance with accepted academic practice. No use, distribution or reproduction is permitted which does not comply with these terms. 